\title{
A NEW STABILITY-INDICATING RP-HPLC-PDA METHOD FOR SIMULTANEOUS ESTIMATION OF TRIPLICATE MIXTURE OF RAMIPRIL, ATORVASTATIN AND CLOPIDOGREL IN TABLET DOSAGE FORM
}

\author{
SUBBA RAO ${ }^{1}$, B. BALASWAMI ${ }^{*}$, P. VENKATA RAMANA ${ }^{2}$, P. SANJEEVA ${ }^{3}$, G. SRENIVASULAREDDY ${ }^{4}$ \\ Department of Chemistry, Sri Krishnadevaraya University, Ananthapuramu 515003, A. P, India \\ Email: balaswamypgt@gmail.com
}

Received: 26 Apr 2018, Revised and Accepted: 02 Jul 2018

\section{ABSTRACT}

Objective: To develop a novel, accurate, precise and linear reverse phase high performance liquid chromatographic (RP-HPLC) method for simultaneous quantitative estimation of ramipril, atorvastatin and clopidogrel in Atamra-CV tablet and validate as per international conference on harmonization (ICH) guidelines and to perform the force degradation studies using the developed method.

Methods: In the present work, the good chromatographic separation was achieved isocratically using a shim-pack HPLC Kromasil 150 mm x 4.6 $\mathrm{mm}, 5 \mathrm{~m}$. $\mu$. And mobile phase consisting of $0.05 \mathrm{M}$ potassium dihydrogen orthophosphate $\mathrm{pH} 3$ adjusted with orthophosphoric acid and acetonitrile in the ratio (52:48), at flow rate $1 \mathrm{ml} / \mathrm{min}$ and column temperature $\left(30^{\circ} \mathrm{C}\right)$. The effluents obtained were monitored at $210 \mathrm{~nm}$ with the $\mathrm{UV}$-visible detector.

Results: The retention time of ramipril, atorvastatin and clopidogrel was found to be $2.893 \mathrm{~min}, 5.012 \mathrm{~min}$ and $6.102 \mathrm{~min}$ respectively. The linearity of ramipril, atorvastatin and clopidogrel was found in the range of $25-150 \%$ and the correlation coefficient for ramipril, atorvastatin and clopidogrel were $>0.999$. The high recovery values (98\%-101\%) indicate a satisfactory accuracy. The low percent relative standard deviation (\% RSD) values in the precision study reveals that the method is precise. The three-drug samples were subjected to stress conditions of acidic and alkaline hydrolysis, oxidation, photolysis and thermal degradation. The proposed method proved to be stability-indicating by resolution of the analytes from their forced-degradation products.

Conclusion: The developed method is novel, simple, precise, rapid, accurate and reproducible for simultaneous estimation of ramipril, atorvastatin and clopidogrel tablet dosage form. Hence the proposed method may find practical applications as a quality-control tool in the simultaneous analysis of the three drugs in combined dosage forms in quality-control laboratories. The proposed method was made use of photodiode array (PDA) as a tool for peak identification and purity confirmation.

Keywords: Ramipril, Atorvastatin, Clopidogrel, RP-HPLC method development, Validation

(C) 2018 The Authors. Published by Innovare Academic Sciences Pvt Ltd. This is an open access article under the CC BY license (http://creativecommons.org/licenses/by/4.0/) DOI: http://dx.doi.org/10.22159/ijap.2018v10i5.26945

\section{INTRODUCTION}

Ramipril is an angiotensin-converting enzyme (ACE) inhibitor, used to treat hypertension and congestive heart failure. It acts on the reninangiotensin system [1-2]. Ramipril is an anti-hypertensive agent [3-4] and chemically $(1 \mathrm{~S}, 5 \mathrm{~S}, 7 \mathrm{~S})-8-[(2 \mathrm{~S})-2-[[(\mathrm{IS})-1$-ethoxycarbonyl-3phenylpropvl] amino] propanovl]-8-azabicvclo [330] octane-7carboxylic acid [5-8]. It blocks the counter-regulatory rise in Angiotensin-II triggered by diuretic theory [9-10]. The structure of ramipril was shown in (fig. 1a) Atorvastatin calcium is a selective, competitive HMG-CoA reductase inhibitor [11-12], is used to lower cholesterol and triglycerides in patients with hypercholesterolemia and mixed dyslipidemia and in the treatment of homozygous familial hypercholesterolemia [7]. It is chemically known as $(\beta R, 8 \mathrm{R})-2-(4-$ fluorophenyl)- $\alpha, \quad \delta$-dihydroxy-5-(1-methylethyl)-3-phenyl-4-[(phenyl amino) carbonyl] 1H-pyrrole-1-heptanoic acid trihydrate [13-14]. It lowers lipid levels by inhibiting HMG-CoA reductase, a rate-limiting enzyme in cholesterol biosynthesis in the liver, thus reducing the cholesterol content in hepatocytes [15]. Antihypertensive and lipidlowering medications substantially reduce the risk of stroke, coronary artery disease (CAD), and death in patients with cardiovascular risk factors [16-17]. Clopidogrel bisulfate is chemically (+)-(S)-(2chlorophenyl)-6,7-dihydrothieno [3,2-c] pyridine-5 (4H) acetic acid methyl ester sulphate is a potent oral antiplatelet agent often used for the treatment of CAD, peripheral vascular disease (PVD) and cerebrovascular diseases (CVD). Since it is a prodrug, it must be metabolized by CYP450 enzymes to produce the active metabolite that inhibits platelet aggregation. This active metabolite selectively inhibits adenosine diphosphate (ADP) binding to its platelet P2Y12 receptor and subsequently the ADP-mediated activation of the glycoprotein GPIIb/IIIa complex, thereby inhibiting platelet aggregation [18-20].
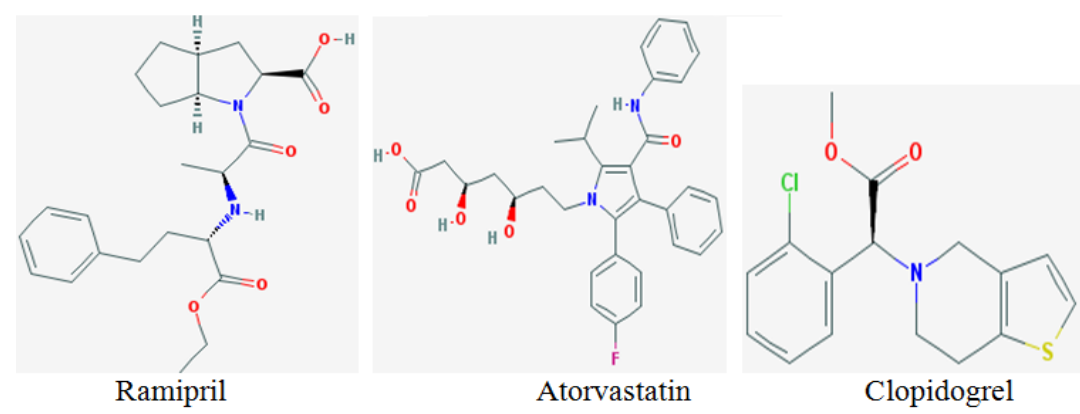

Fig. 1: Chemical structure of (a) Ramipril (b) Atorvastatin (c) Clopidogrel 
As per the literature survey several methods have been reported for the estimation of ramipril, atorvastatin, and clopidogrel individually or with the combination of some other drugs. Some of the methods were being; simultaneous estimation of atorvastatin, clopidogrel [21-22] ramipril, atorvastatin [23-24]. There is no official method for this combination so far as per our knowledge. The present proposed method estimates ramipril, atorvastatin, and clopidogrel in a simple and economical process. The main aim of this method was to determine and validate the ramipril, atorvastatin and clopidogrel based on International Conference on Harmonization [25-27] guidelines. This method was made use of a reproducible procedure for the quantitative analysis of drug samples as the bulk drug and in tablet dosage forms. The designed method was considered as an advisable to develop precise, accurate, a simple RPHPLC method for stability indicating and simultaneous estimation of ramipril, atorvastatin and clopidogrel in tablets.

\section{MATERIALS AND METHODS}

\section{Instrumentation}

The analysis was performed on an HPLC instrument used was of Kromasil $150 \mathrm{~mm}$ x $4.6 \mathrm{~mm}, 5 \mathrm{~m}$. $\mu$. With Auto-Injector and PDA Detector and it was controlled by using software Empower 2. and it has UV-VIS spectrophotometer PG Instruments T60 with a special bandwidth of $2 \mathrm{~mm}$ and $10 \mathrm{~mm}$ and matched quartz was be used for measuring absorbance for ramipril, atorvastatin and clopidogrel solutions. The separation and quantization were made on column (Kromasil $150 \mathrm{~mm} \times 4.6 \mathrm{~mm}, 5 \mathrm{m \mu}$ ).

\section{Materials}

HPLC grade acetonitrile, water was secured from Ranbaxy, India, and orthophosphoric acid AR grade was purchased from SD Fine Chem. Mumbai, India were used in the study and supported by the literature. The drug samples were kindly supplied by Spectrum Pharmaceuticals Pvt Ltd, Kukutpally, Hyderabad, India, and the formulation samples analytical grade of orthophosphoric acid, sodium hydroxide, hydrochloric acid, hydrogen peroxide and high purity distilled water were used. The preparation of three drugs was Atamra-CV tablets labeled claim was $5 \mathrm{mg}$ of ramipril, $10 \mathrm{mg}$ of atorvastatin and $75 \mathrm{mg}$ of clopidogrel.

\section{General procedure}

\section{Chromatographic conditions}

A mobile phase system consisting of buffer and acetonitrile was used in the ratio of $52: 48 \mathrm{~A} \% \mathrm{~V} / \mathrm{V}$ at a $\mathrm{pH} 3$ adjusted with orthophosphoric acid and water and methanol in the ratio of $50: 50 \mathrm{~V} / \mathrm{V}$ used as diluents for preparing the working solutions of drug. The separation was achieved with the elution method. The flow rate was $1.0 \mathrm{ml} / \mathrm{min}$. The injection volume was $10 \mathrm{ml}$. The eluant was monitored by the photo diode array detector (PDA) from 200 to $400 \mathrm{~nm}$, and chromatograms were extracted at the wavelengths of $210 \mathrm{~nm}$. The total run time was $11 \mathrm{~min}$, and all establishments were performed at $30^{\circ} \mathrm{C}$.

\section{Standard solutions}

Accurately Weighed and transferred $6 \mathrm{mg}, 6 \mathrm{mg}$ and $18 \mathrm{mg}$ of ramipril, atorvastatin and clopidogrel working Standards into a 50 $\mathrm{ml}, 25 \mathrm{ml}$ and $10 \mathrm{ml}$ clean dry volumetric flask, add $5 \mathrm{ml}$ of diluents, sonicated for $30 \mathrm{~min}$ and made up to the final volume with diluents to obtain the concentrations of $12 \mu \mathrm{g} / \mathrm{ml}$ ramipril, $24 \mu \mathrm{g} / \mathrm{ml}$ atorvastatin and $180 \mu \mathrm{g} / \mathrm{ml}$ of clopidogrel.

From the above stock solutions, $1 \mathrm{ml}$ was pipette out in to a $10 \mathrm{ml}$ volumetric flask and then made up to the final volume with diluents and achieved concentrations 12, 24 and $180 \mu \mathrm{g} / \mathrm{ml}$. Three injections were finished for each concentration and chromatographs were gained under the previously described liquid chromatographic conditions. The peak areas were plotted in opposition to the consequent concentrations to erect the calibration graphs.

\section{Assay of sample preparation}

Six Atamra-CV tablets were weighed and calculated the average weight of each tablet then the weight equivalent to 1 tablet was transferred into a $100 \mathrm{ml}$ volumetric flask, $70 \mathrm{ml}$ of diluents added and sonicated for $30 \mathrm{~min}$, further the volume made up with diluents and filtered. From the filtered solution $0.4 \mathrm{ml}$ was pipette out into a $10 \mathrm{ml}$ volumetric flask and made up to10 $\mathrm{ml}$ with diluents and acquired final concentrations were 12,24 and $180 \mu \mathrm{g} / \mathrm{ml}$ for ramipril, atorvastatin and clopidogrel respectively. These specified concentrations were used for general procedure and recovered concentrations were calculated from the consequent calibration graphs. For regular addition assay, test solutions were spiked with aliquots of regular solutions of the three compounds to gain total concentrations contained by the earlier specified ranges then treated as under common process. Recovered concentrations were deliberated by assimilating the analyte response with the growth response achieved after addition of the standard.

\section{Method validation procedure}

The method was validated as per ICH guidelines [25-27]. The different validation parameters which were performed are following: system suitability, linearity, precision, accuracy, specificity, and limit of detection, limit of quantification, robustness, degradation studies and the stability indicating capability.

\section{Stability-indicating and forced degradation studies}

Forced degradation studies were executed on ramipril, atorvastatin and clopidogrel standards based on the following conditions:

\section{Oxidation}

To $1 \mathrm{ml}$ of stock solution of ramipril, atorvastatin and clopidogrel and $1 \mathrm{ml}$ of $20 \%$ hydrogen peroxide $\left(\mathrm{H}_{2} \mathrm{O}_{2}\right)$ were added separately. The solutions were kept for $30 \mathrm{~min}$ at $60^{\circ} \mathrm{C}$. For HPLC study, the resultant solution was diluted to obtain concentrations 12, 24 and $184 \mu \mathrm{g} / \mathrm{ml}$. A solution of $10 \mu \mathrm{l}$ was injected into the system and the chromatograms were recorded to assess the stability of sample.

\section{Acid degradation studies}

To $1 \mathrm{ml}$ of stock solution of ramipril, atorvastatin and clopidogrel and $1 \mathrm{ml}$ of $2 \mathrm{~N}$ Hydrochloric acid was added and refluxed for $30 \mathrm{~min}$ at 60 ${ }^{\circ} \mathrm{C}$. The resultant solution was diluted to obtain concentrations 12, 24 and $184 \mu \mathrm{g} / \mathrm{ml}$. A solution of $10 \mu \mathrm{l}$ was injected into the system and the chromatograms were recorded to assess the stability of sample.

\section{Alkali degradation studies}

To $1 \mathrm{ml}$ of stock solution of ramipril, atorvastatin and clopidogrel and $1 \mathrm{ml}$ of $2 \mathrm{~N}$ sodium hydroxide was added and refluxed for $30 \mathrm{~min}$ at $60^{\circ} \mathrm{C}$. The resultant solution was diluted to obtain concentrations $12 \mu \mathrm{g} / \mathrm{ml}, 24 \mu \mathrm{g} / \mathrm{ml}$ and $184 \mu \mathrm{g} / \mathrm{ml}$. A solution of $10 \mu \mathrm{l}$ was injected into the system and the chromatograms were recorded to assess the stability of sample.

\section{Dry heat degradation studies}

The standard stock solution was placed in oven at $105^{\circ} \mathrm{C}$ for $6 \mathrm{~h}$ to study dry heat degradation. For HPLC study, the resultant solution was diluted to obtain concentrations $12 \mu \mathrm{g} / \mathrm{ml}, 24 \mu \mathrm{g} / \mathrm{ml}$ and 184 $\mu \mathrm{g} / \mathrm{ml}$ for ramipril, atorvastatin and clopidogrel. A solution of $10 \mu \mathrm{l}$ was injected into the system and the chromatograms were recorded to assess the stability of the sample.

\section{Photo stability studies}

The photochemical stability of the drugs were also studied by exposing the concentrations of $12 \mu \mathrm{g} / \mathrm{ml}, 24 \mu \mathrm{g} / \mathrm{ml}$ and $184 \mu \mathrm{g} / \mathrm{ml}$ solution to UV Light by keeping the beaker in UV Chamber for $7 \mathrm{~d}$ or 200 Watt hours/m2in photostability chamber. For HPLC study, the resultant solution was diluted to obtain $12 \mu \mathrm{g} / \mathrm{ml}, 24 \mu \mathrm{g} / \mathrm{ml}$ and $184 \mu \mathrm{g} / \mathrm{ml}$ concentrated solutions and $10 \mu \mathrm{l}$ were injected into the system and the chromatograms were recorded to assess the stability of the sample.

\section{Neutral degradation studies}

Stress testing under neutral conditions was studied by refluxing the drugs in water for $6 \mathrm{~h}$ at a temperature of $60^{\circ} \mathrm{C}$. For HPLC study, the resultant solution was diluted to $12 \mu \mathrm{g} / \mathrm{ml}, 24 \mu \mathrm{g} / \mathrm{ml}$ and $184 \mu \mathrm{g} / \mathrm{ml}$ concentrated solutions and $10 \mu \mathrm{l}$ were injected into the system and the chromatograms were recorded to assess the stability of the sample. 


\section{RESULTS AND DISCUSSION}

A simple, rapid and precise method has been developed and validated for the drug ramipril, atorvastatin and clopidogrel. There is no official method for this combination so far. However, few methods have been reported in either of one or two in this combination with some other drugs. On comparison with literature, it is found that Mobile phase used by SM Patole et al. [6] used methanol and acetate buffer. Rajesh Sharma et al. [7] Gurupadayya et al. [18] were phosphate buffer and acetonitrile methanol. Nitin dubey et al. [28] used methanol, acetonitrile and water. Sahityasundar et al. [29] used acetonitrile, methanol and trimethylamine. The buffers in the mobile phases used in all the methods take more preparation time and also the usage of buffers reduces the life of column. The retention time of drugs in the methods developed by SM Patole et al. [6] $5.80 \mathrm{~min}$ for ramipril and $8.20 \mathrm{~min}$ for atorvastatin. Rajesh Sharma et al. [7] 3.620 and 11.710 min for ramipril and atorvastatin. Gurupadayya et al. [18] $8.2 \mathrm{~min}$ for clopidogrel. Nitin dubey et al. [28] $11.820 \mathrm{~min}$ for clopidogrel and $15.620 \mathrm{~min}$ for atorvastatin. Sahityasundar et al. [29] $3.8 \mathrm{~min}$ for atorvastatin and $7.4 \mathrm{~min}$ for clopidogrel thereby increasing the analysis time.
In the proposed method a simple mobile phase consisting of buffer and acetonitrile was used which elute the ramipril, atorvastatin and clopidogrel with lower retention time. The retention times were $2.903 \mathrm{~min}, 5.005 \mathrm{~min}$ and 6.134 for ramipril, atorvastatin and clopidogrel respectively. The calibration curve was linear over the concentration range of $25-150 \mathrm{ppm}$. The LOD values were $0.29,0.35$ and1.97 and LOQ values were found to be $0.89,1.07$ and 5.98 for ramipril, atorvastatin and clopidogrel respectively. The high percentage of recovery and low percentage coefficient of variance confirm the suitability of the method and the forced degradation studies shows that the developed method was stability indicating. Hence it was concluded that the RP-HPLC method developed was highly suitable for routine analysis and all the parameters result data was shown in method validation systematically.

\section{Method development}

Six trials were performed for the method development and the best peaks with least fronting factor was elevated for ramipril, atorvastatin and clopidogrel to be with retention times were 2.903 , $5.005,6.134 \mathrm{~min}$ respectively. The resultant chromatogram revealed in the fig. 2 .

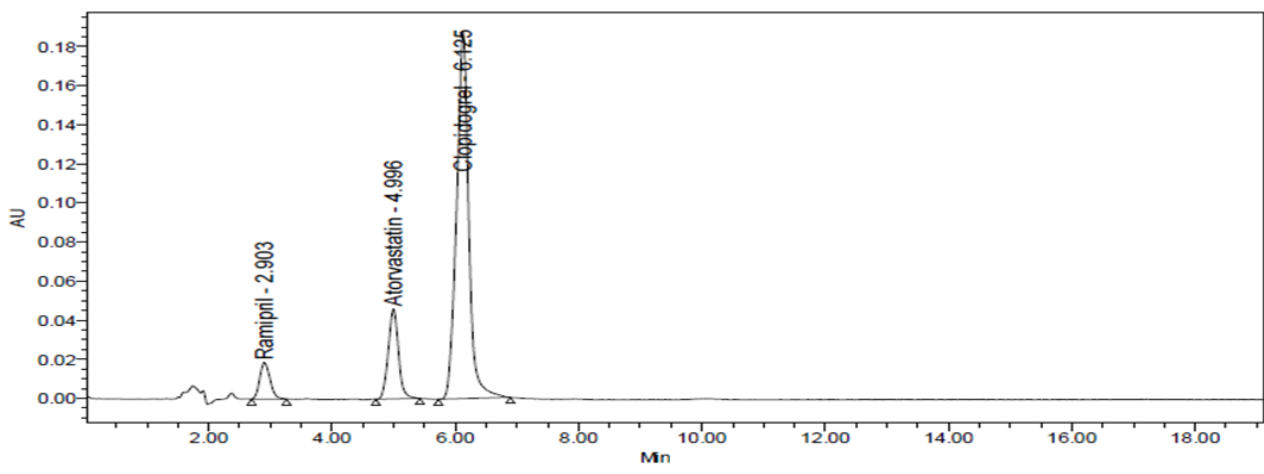

Fig. 2: Sample chromatogram of ramipril, atorvastatin and clopidogrel

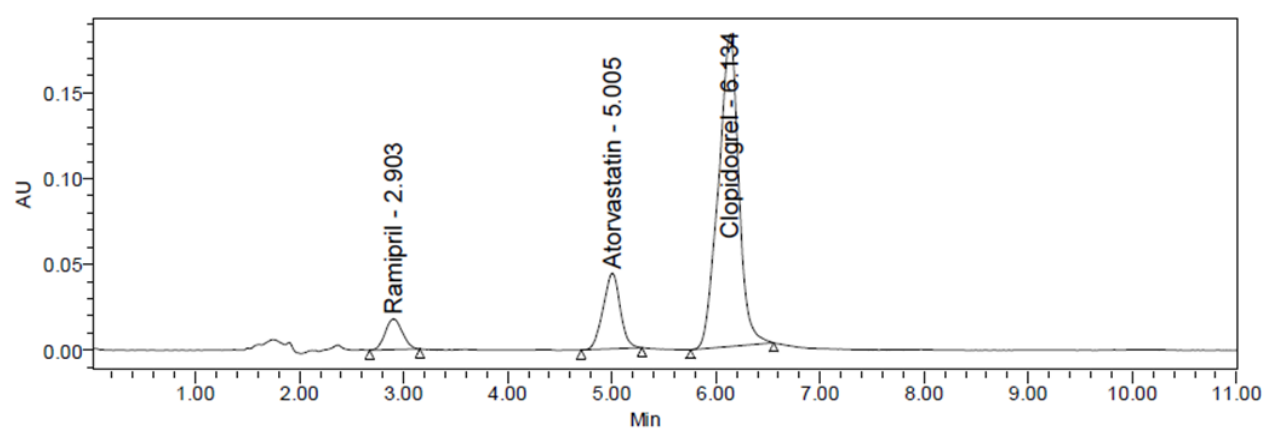

Fig. 3: Standard chromatogram of ramipril, atorvastatin and clopidogrel

\section{Method validation}

\section{System suitability test}

Six replicate injections of standard solutions were injected and the chromatograms were recorded. The system was suitable for analysis of ramipril, atorvastatin and clopidogrel if the \% relative standard deviation (\% RSD) of area counts in six repeated injections should be not more than $2.0 \%$. USP tailing factor for ramipril, atorvastatin and clopidogrel peak should be not more than 2.0. USP resolution factor between the peaks corresponding to ramipril, atorvastatin and clopidogrel should be more than 2.0. The results are shown in the table 1.

Table 1: System suitability results

\begin{tabular}{llll}
\hline Parameter & Ramipril & Atorvastatin & Clopidogrel \\
\hline USP tailing Factor & 1.07 & 0.96 & 0.93 \\
USP plate count & 1391 & 3899 & 4037 \\
$\mathrm{LOD}(\mu \mathrm{g} / \mathrm{ml})$ & 0.29 & 0.35 & 1.97 \\
$\mathrm{LOQ}(\mu \mathrm{g} / \mathrm{ml})$ & 0.89 & 1.07 & 5.98 \\
$\% \mathrm{RSD}$ & 0.7 & 0.6 & 0.5 \\
\hline
\end{tabular}




\section{Linearity and concentration ranges}

Working dilutions of ramipril, atorvastatin and clopidogrel was 25 to $150 \%$ was prepared by taking suitable aliquots of solutions of drug in several $10 \mathrm{ml}$ volumetric flask and made up to the mark with mobile phase and those are depicted in table 2. $10 \mu \mathrm{l}$ amount of every dilution was injected in to the column with a flow rate of 1 $\mathrm{ml} / \mathrm{min}$. The samples in elute were monitored at $210 \mathrm{~nm}$ and the subsequent chromatograms were recorded. From these, calculated the mean peak areas and showed in table- 3 for ramipril, atorvastatin and clopidogrel a plot of concentration vs peak areas was produced and drawn in the fig. 4, 5 and 6. The regression of the plot was calculated by least square regression method. Regression equation of ramipril was $\mathrm{y}=17045 \mathrm{x}+1518\left(\mathrm{R}^{2}=0.999\right)$, atorvastatin was $\mathrm{y}=$ $21828 \mathrm{x}+2328 \quad\left(\mathrm{R}^{2}=0.999\right)$ clopidogrel was $\mathrm{y}=13555 \mathrm{x}+8103$ $\left(R^{2}=0.999\right)$ and also the results were presented in table 3 .

Table 2: Linearity concentration table

\begin{tabular}{|c|c|c|c|c|c|c|}
\hline $\begin{array}{l}\text { S. } \\
\text { No. }\end{array}$ & $\begin{array}{l}\text { Pipetted from } \\
\text { stock (ml) }\end{array}$ & $\begin{array}{l}\text { Volume of } \\
\text { flask }(\mathrm{ml})\end{array}$ & $\begin{array}{l}\text { Concentration in ppm } \\
\text { (ramipril) }\end{array}$ & $\begin{array}{l}\text { Concentration in ppm } \\
\text { (Atorvastatin) }\end{array}$ & $\begin{array}{l}\text { Concentration in ppm } \\
\text { (Clopidogrel) }\end{array}$ & $\begin{array}{l}\text { \% linearity } \\
\text { level }\end{array}$ \\
\hline 1 & 0.25 & 10 & 3 & 6 & 45 & 25 \\
\hline 2 & 0.5 & 10 & 6 & 12 & 90 & 50 \\
\hline 3 & 0.75 & 10 & 9 & 18 & 135 & 75 \\
\hline 4 & 1 & 10 & 12 & 24 & 180 & 100 \\
\hline 5 & 1.25 & 10 & 15 & 30 & 225 & 125 \\
\hline 6 & 1.5 & 10 & 18 & 36 & 270 & 150 \\
\hline
\end{tabular}

Table 3: linearity peak area values of ramipril, atorvastatin and clopidogrel

\begin{tabular}{lllll}
\hline S. No. & concentration & Peak areas of ramipril & Peak areas of atorvastatin & Peak areas of clopidogrel \\
\hline 1 & 25 & 56110 & 134192 & 630356 \\
2 & 50 & 103767 & 262687 & 1241964 \\
3 & 75 & 156441 & 399126 & 1845601 \\
4 & 100 & 201249 & 527033 & 2406287 \\
5 & 125 & 254148 & 659598 & 3049912 \\
6 & 150 & 312733 & 783975 & 3691858 \\
\hline
\end{tabular}

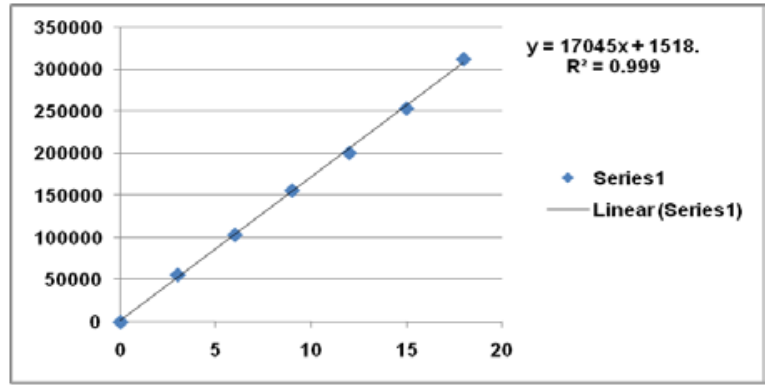

Fig. 3: Linearity graph for ramipril

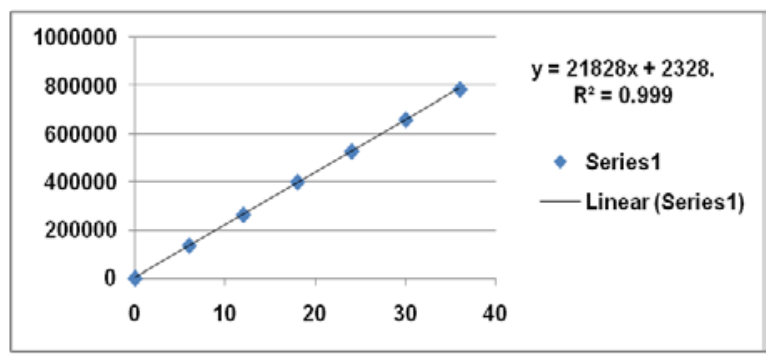

Fig. 4: Linearity graph for atorvastatin

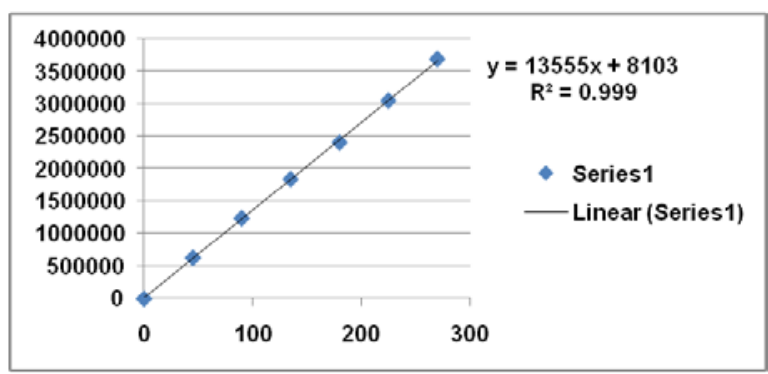

Fig. 5: Linearity graph for clopidogrel, $\mathrm{X}$-Axis = Concentration, Y-Axis = peak area 


\section{Precision}

The standard ramipril, atorvastatin and clopidogrel solutions were injected for six times and measured the area for all six trails in RPHPLC. The \%RSD for the area of six repeat injections was founded to be within the specific limits. The data of system precision was shown in the table 4 , repeatability was presented in table 5 , and inter day precision was showed in table 6 .

Acceptance Criteria: The \% RSD should not be more than $2 \%$

Table 4: Precision results of system

\begin{tabular}{llll}
\hline S. No. & Area of ramipril & Area of atorvastatin & Area of clopidogrel \\
\hline 1 & 208249 & 524974 & 2406287 \\
2 & 207249 & 522689 & 2495508 \\
3 & 209523 & 528939 & 2499346 \\
4 & 209845 & 522427 & 2486225 \\
5 & 206360 & 520971 & 2527346 \\
6 & 208360 & 527033 & 2517161 \\
Mean & 208264 & 524506 & 2488646 \\
SD & 1322.8 & 3045.5 & 43037.7 \\
\%RSD & 0.64 & 0.58 & 1.73 \\
\hline
\end{tabular}

$\mathrm{n}=6$; SD denotes for standard deviation; RSD denotes for relative standard deviation.

Table 5: Repeatability results

\begin{tabular}{llll}
\hline S. No. & Area of ramipril & Area of atorvastatin & Area of clopidogrel \\
\hline 1 & 210787 & 516694 & 2519164 \\
2 & 209879 & 530243 & 2509185 \\
3 & 208496 & 530243 & 2499346 \\
4 & 206680 & 520780 & 2460405 \\
5 & 208144 & 522780 & 2477286 \\
6 & 210602 & 523716 & 2482551 \\
Mean & 209098 & 524076 & 2491323 \\
S. D & 1463.1 & 5352.2 & 21856.1 \\
\%RSD & 0.70 & 1.02 & 0.88 \\
\hline
\end{tabular}

$\mathrm{n}=6$; SD denotes for standard deviation; RSD denotes for relative standard deviation.

Table 6: Inter day precision results

\begin{tabular}{llll}
\hline S. No. & Area of ramipril & Area of atorvastatin & Area of clopidogrel \\
\hline 1 & 210502 & 512725 & 2547431 \\
2 & 210637 & 509879 & 2578002 \\
3 & 213167 & 51784401 & 2593673 \\
4 & 209196 & 528881 & 2548908 \\
5 & 212468 & 514777 & 2579421 \\
6 & 212764 & 521027 & 2546590 \\
Mean & 211456 & 517522 & 2565671 \\
SD & 1571.7 & 6787.9 & 20508.6 \\
\%RSD & 0.7 & 1.3 & 0.8 \\
\hline
\end{tabular}

$\mathrm{n}=6$; SD denotes for standard deviation; RSD denotes for relative standard deviation.

\section{Accuracy}

Accuracy of the readings was computed by \% recovery of six different concentrations of ramipril, atorvastatin and clopidogrel at 50\%, 100\% and $150 \%$ and also standard addition technique was carried out for same samples. The results acquired including the means of the recovery and standard deviations were displayed in table 7.

Acceptance Criteria: The \% Recovery for ramipril, atorvastatin and clopidogrel at each stage should be between 99 to $101 \%$.

Table 7: Accuracy expressed as \% recovery of three drugs by the proposed method

\begin{tabular}{|c|c|c|c|c|c|c|c|c|c|}
\hline \multirow[b]{2}{*}{$\%$ Concentration } & \multicolumn{3}{|c|}{ Ramipril } & \multicolumn{3}{|c|}{ Atorvastatin } & \multicolumn{3}{|c|}{ Clopidogrel } \\
\hline & 50 & 100 & 150 & 50 & 100 & 150 & 50 & 100 & 150 \\
\hline Trail-I & 101.07 & 100.65 & 99.80 & 99.53 & 99.54 & 99.63 & 100.84 & 99.80 & 100.15 \\
\hline Trail-II & 99.78 & 100.12 & 100.11 & 99.03 & 99.69 & 100.07 & 99.71 & 99.50 & 100.13 \\
\hline Trail-III & 99.81 & 100.18 & 100.58 & 100.52 & 100.44 & 100.22 & 98.32 & 100.35 & 99.60 \\
\hline AVG (\% recovery) & 100.22 & 100.32 & 100.17 & 99.70 & 99.89 & 99.97 & 99.62 & 99.88 & 99.96 \\
\hline SD & 0.74 & 0.29 & 0.39 & 0.76 & 0.48 & 0.31 & 1.26 & 0.43 & 0.31 \\
\hline$\%$ RSD & 0.74 & 0.29 & 0.39 & 0.76 & 0.48 & 0.31 & 1.26 & 0.43 & 0.31 \\
\hline
\end{tabular}

$\mathrm{n}=3$; AVG denotes average; SD denotes for standard deviation; RSD denotes for relative standard deviation 


\section{Recovery studies}

To estimate the accuracy and precision of the proposed method recovery studies were carried out. A fixed amount of sample was taken and reference drugs were added at $50 \%, 100 \%$ and $150 \%$ levels. The results were analyzed and the results were within the limits.

\section{Specificity}

The specificity of the RP-HPLC method is furnished, where complete separations of ramipril, atorvastatin and clopidogrel were distinguished in presence of other inert excipients used in tablets. In addition, there was no deterrence at the retention time of in the chromatogram of placebo solution. In the case of peak purity analysis with PDA, purity gradient was always not greater than purity threshold for the analytes. This shown that the peaks of analyte were pure and excipients in the formulation does not interfere the analyte. The data were listed in the table 8.

\section{Limit of detection and limit of quantification}

Limit of Detection (LOD) is the least concentration of an analyte in a sample that can be identified but not quantified. LOD is indicated as a concentration at a précised signal to noise ratio. The LOD will depend on the procedure of analysis along with type of instrument. In the chromatography, detection limit is the injected quantity that consequences in a peak with a height at least thrice or twice as high as baseline noise level. LOD was computed by using formula LOD $=3.3\left(\frac{S D}{\mathrm{~S}}\right)$

The LOD was found to be $0.29,0.35$ and 1.97 for ramipril, atorvastatin and clopidogrel respectively.

Limit of quantification (LOQ) is defined as least concentration of analyte in a sample that can be estimated with tolerable precision, accuracy and reliability by a specified method under affirmed experimental conditions. LOQ is uttered as a concentration at a specified signal to noise ratio. In the chromatography, limit of quantification is the injected quantity that consequences in a peak with a height, ten times as high as base line noise level. LOQ is calculated by using the formula $\mathrm{LOQ}=10\left(\frac{\mathrm{SD}}{\mathrm{S}}\right)$

The LOQ was found to be $0.89,1.07$ and 5.98 for ramipril, atorvastatin and clopidogrel respectively.

\section{Robustness}

Robustness is denoted by making speculate changes in the chromatographic conditions like change in temperature, mobile phase composition and flow rate were assessed for the impact on the present method. It was founded from the chromatograms that the results were not exceeding the limits. This represents that the method developed is robust and shown in the table 9 .

Table 8: Specificity results for ramipril, atorvastatin and clopidogrel

\begin{tabular}{|c|c|c|c|c|c|}
\hline S. No. & Name of the sample & No. of injections & Area of ramipril & Area of atorvastatin & Area of clopidogrel \\
\hline 1 & Blank & 1 & - & - & - \\
\hline 2 & Placebo & 1 & - & - & - \\
\hline 3 & Standard & 1 & 208249 & 524974 & 2406287 \\
\hline 4 & Water sample & 1 & 206846 & 512140 & 2502060 \\
\hline
\end{tabular}

Table 9: Robustness of ramipril, atorvastatin and clopidogrel

\begin{tabular}{llll}
\hline Parameter & & Ramipril & Atorvastatin \\
\hline Temperature \pm 5 & 25 & 204346 & 496627 \\
& 35 & 206505 & 491383 \\
Flow rate \pm 0.1 & 0.9 & 203495 & 486072 \\
& 1.1 & 202758 & 481871 \\
Mobile Phase change \pm 5 & $48: 52$ & 200842 & 482383 \\
& $57: 53$ & 201772 & 2407038 \\
\hline
\end{tabular}

\section{Degradation studies}

The forced degradation studies were conceded out to ensure the effective separation of ramipril, atorvastatin and clopidogrel in the current study from degradation products. The degradation was observed by reducing the peak areas of the drug substances with same drug molecules of degraded peak areas. The percentage assay of degradation was calculated from the peak area obtained in degradation conditions and it was compared with assay of nondegraded conditions. The percentage assay degradation in both acidic and alkali conditions was found to be within the limits. Oxidative degradation studies were performed by using peroxide solution and the results showed that there was no degradation products formed. The drug solutions were placed in oven at $105^{\circ} \mathrm{C}$ for $6 \mathrm{~h}$ for thermal stress studies and then injected into HPLC system and photo stress testing was carried out by keeping the drug solutions in UV chamber for $7 \mathrm{~d}$. The purity of angle is found to be less than that of purity of threshold in all the conditions which indicates that the developed method was stability indicating. The forced degradation studies were performed without planning to recognize the degradation products but only to show that they are not interfering with active molecules if any present. The data of stress studies are shown in table 10.

Table 10: Degradation studies of ramipril, atorvastatin and clopidogrel

\begin{tabular}{|c|c|c|c|c|c|c|c|}
\hline \multirow[t]{2}{*}{ Sample name } & \multirow[t]{2}{*}{ Total purity } & \multicolumn{2}{|l|}{ Ramipril } & \multicolumn{2}{|l|}{ Atorvastatin } & \multicolumn{2}{|l|}{ Clopidogrel } \\
\hline & & $\%$ of purity & $\begin{array}{l}\text { Purity of peak } \\
\text { area }\end{array}$ & $\%$ of purity & $\begin{array}{l}\text { Purity of peak } \\
\text { area }\end{array}$ & $\%$ of Purity & $\begin{array}{l}\text { Purity of peak } \\
\text { area }\end{array}$ \\
\hline Acid & 100 & 92.24 & 204612 & 92.20 & 500136 & 92.05 & 2439614 \\
\hline base & 100 & 93.42 & 204122 & 93.44 & 497716 & 93.12 & 2456551 \\
\hline peroxide & 100 & 94.05 & 205592 & 94.47 & 503765 & 94.09 & 2471387 \\
\hline thermal & 100 & 95.13 & 201373 & 95.60 & 497829 & 95.57 & 2441639 \\
\hline uv & 100 & 98.98 & 204288 & 98.68 & 501125 & 98.40 & 2459190 \\
\hline Water & 100 & 99.37 & 204177 & 99.32 & 500977 & 99.85 & 2452886 \\
\hline
\end{tabular}




\section{CONCLUSION}

The current study describes new and simple, reliable, economic elution RP-HPLC-PDA method for the simultaneous estimation of ramipril, atorvastatin and clopidogrel. The forced degradation studies were conducted for the three drugs by using several degradation conditions like oxidation, acidic, alkali, thermal, and photolytic conditions and proposed method was effectively employed from the resolution of employed samples peaks. To our present knowledge, no such detailed and stability indicating method has been presented for the assay of this triplicate drug mixture. The developed method finished use of PAD as a tool for peak integrity and purity confirmation. Therefore the proposed study method can be used for quantification of ramipril, atorvastatin and clopidogrel in bulk and pharmaceutical dosage form. Finally, this method was carefully validated; as a result, it can be suggested for routine analysis and for testing quality through stability studies of the drugs.

\section{AUTHORS CONTRIBUTIONS}

All the authors have contributed equally

\section{CONFLICT OF INTERESTS}

The authors have no conflict of interest

\section{REFERENCES}

1. Goodman, Gilman. The Pharmacological basis of therapeutics. 10th ed. New York: McGraw Hill Book; 2001. p. 1701.

2. Warner TG, Perry MC. Ramipril: a review of its use in the prevention of cardiovascular outcomes. Drugs 2002;62:1381-405.

3. Andal NJK, Mohangandhi B, Bhaskararaju V, Srinivassumanth $\mathrm{K}$, Venkatakoteswaramma K, Srinivas K, et al. Development and validation of stability indicating RP-HPLC method for simultaneous estimation of ramipril, aspirin and simvastatin in bulk and pharmaceutical dosage form. Asian J Biomed Pharm Sci 2016;6:14-20.

4. Vaibhav R, Amrita S, Varsha K. Method development and validation of fast dissolving tablet of ramipril by HPLC method. Int J Pharm Sci 2016;8:174-8.

5. Indian Pharmacopoeia. The controller of publication Govt. of India, New Delhi; 2007.

6. Patole SM, Potale1 LV, Khodke AS, Damle MC. Validated HPLC method for analysis of atorvastatin calcium, ramipril and aspirin as the bulk drug and in combined capsule dosage forms. Int J Pharma Sci Rev 2010;4:40-5.

7. Rajesh S, Sunil K, Ganesh PM. Development and Validation of RP-HPLC method for simultaneous estimation of ramipril, aspirin and atorvastatin in pharmaceutical preparations. E J Chem 2012;9:2177-84.

8. Kamatchi Sankar AS, Thangarasu V, Venkappaya D. Simultaneous estimation of ramipril, acetylsalicylic acid and atorvastatin calcium by chemometrics assisted UVspectrophotometric method in capsules. Acta Pharm 2011; 61:283-96.

9. Patel RB, Shankar MB, Patel MR, Bhatt KK. Simultaneous estimation of acetylsalicylic acid and clopidogrel bisulfate in pure powder and tablet formulations by high-performance column liquid chromatography and high-performance thinlayer chromatography. J AOAC Int 2008;91:750-5.

10. Jinesh Bahubali N, Preethi Anantharaju G. Analytical RP-HPLC method development and validation for the simultaneous estimation of ramipril and hydrochlorothiazide in tablet dosage form. Am J PharmTech Res 2014;4:349-65.

11. Budavari, O'Neil, Maryadele J. The merck index an encyclopedia of chemicals, drugs and biologicals. 13th ed. Whitehouse Station: N. J Merck; 2001.
12. Noha I, Mohamaed $\mathrm{R}$, Ahmed I, Shereen $\mathrm{T}$, Inas Ali. Simultaneous determination of amlodipine besylate and atorvastatin calcium by using spectrophotometric method with multivariate calibration and HPLC method implementing " design of experiment". Int J Pharm Sci 2014;6:419-25.

13. Indian Pharmacopoeia: Published by the Controller of Publications. Government of India, Ministry of Health and Family Welfare. Volume I and II. Delhi; 1996.

14. Indian Pharmacopoeia: Ministry of Health and Family Welfare, The Indian Pharmacopoeia commission. Volume I and II. New Delhi: Published by the Government of India; 2007. p. 131, 1036.

15. Martindale: The Complete Drug Reference. 36th edition. London: Pharmaceutical Press; 2009. p. 20, 1218.

16. Budavari S. The Merck Index. 12th ed. White House Station (New Jersey): Merck and Co., Inc.; 1996. p. 146.

17. Reynolds EF, Dale M. The extra pharmacopoeia. $31^{\text {st }}$ ed. London (Britain): Royal Pharmaceutical Society; 1996. p. 1302.

18. Gurupadayya GM, Sindhura S. Bio-analytical determination of clopidogrel and pantoprazole by RP-HPLC method in rat plasma: application to drug interaction study. Asian J Pharm Clin Res 2014;7:10-3.

19. Kim DS, Lee BJ, Yong YJ, Kim JO. Comparison of a solid SMEDDS and solid dispersion for enhanced stability and bioavailability of clopidogrelnapadisilate. J Carb Pol 2014;114:365-74.

20. Marta K, Dorota D, Artur T, Czesław Z, Gilles T. HPLC-MS/MS method for the simultaneous determination of clopidogrel, its carboxylic acid metabolite and derivatized isomers of thiol metabolite in clinical samples. J Chromatogr B 2012;911:105-12.

21. Neela M, Bhatiaa, Gurava SB, Swapnil D, Jadhava, Manish. RPHPLC method for simultaneous estimation of atorvastatin calcium, losartan potassium, atenolol, and aspirin from tablet dosage form and plasma. J Liq Chromatogr Relat Technol 2012;35:428-43

22. Durgarao D, Kalyanaraman L, Sait SS, Venkata Rao P. A validated stability-indicating normal phase LC method for clopidogrel bisulfate and its impurities in bulk drug and pharmaceutical dosage form. J Pharm Biomed Anal 2010;52:160-5.

23. Sheshadri R. Simultaneous quantitative determination of metroprolol, atorvastatin and ramipril in capsules by a validated stability indicating RP-UPLC method. Sci Pharm 2010;78:821-34.

24. Kamatchi Sankar AS, Thangarasu V, Venkappaya D. Simultaneous estimation of ramipril, acetylsalicylic acid and atorvastatin calcium by chemometrics assisted UVspectrophotometric method in capsules. Acta Pharm 2011;61:283-96

25. ICH, Stability testing of new drug substances and products (Q1AR2), International Conference on Harmonization, IFPMA, Geneva; 2003.

26. International Conference on Harmonization of Technical Requirements for Registration of Pharmaceuticals for Human use. Validation of Analytical Procedures: Text and Methodology ICH Q2 (R1); 2005.

27. ICH guidelines for impurities in new drug substances Text and methodology Q3A (R2), International Conference on Harmonization; 2006.

28. Nitin D, Manju P, Dinesh KJ. Simultaneous estimation of aspirin, atorvastatin and clopidogrel in combined capsule dosage form using reverse phase high-performance liquid chromatography. Int J Pharm Biomed Pharm Sci 2013;7:42-4.

29. Sahityasundar R, Valliappan K. New stability indicating assay method by liquid chromatographic separation of aspirin, atorvastatin and clopidogrel in pharmaceutical dosage form. Indo Am J Pharm Res 2014;4:1519-27. 